\title{
A dynamic, network and resource-based approach to the sustainable business model
}

\author{
Anna Ujwary-Gil ${ }^{1}$ (D) Natalia Regina Potoczek ${ }^{1}$ (B)
}

Received: 31 January 2020 / Accepted: 8 July 2020 / Published online: 20 August 2020

(C) The Author(s) 2020

\begin{abstract}
The network perspective of a business model provides an attractive outlook on the interactions and interdependencies of its components. The network is a "living organism," it changes constantly and dynamically. Therefore, the key nodes in the network, and their potential loss, may be of vital importance to the network itself. The paper presents the network of relations between the components of a company business model operating in a sector of new technologies - virtual reality - and indicates the prominent and most influential nodes in the network that can affect value creation. The authors analyzed the influence exerted by a key node that has been eliminated from the network on the remaining structure, based on the immediate impact (change analysis), which computes the key nodes of the network and then isolates them individually to determine the effect on measured values. The primary research approach is an organizational network analysis (mostly centrality measures) and a simulation functionality used for determining measures and visualization, before and after changes. The results indicate the level of centrality measures of all nodes in the network (a virtual reality company's business model), their interdependence, and the dynamics of their change. The paper concludes with implications for theory and practice, limitations, and directions for further research.
\end{abstract}

Keywords Business model $\cdot$ Dynamics $\cdot$ Organizational network analysis $\cdot$ Resources $\cdot$ Sustainability $\cdot$ Virtual reality

JEL classification L20 $\cdot$ D85

\section{Introduction}

\section{Motivation}

The topic of the paper is a dynamic and resource-based approach to a sustainable virtual reality company's business model in which the network perspective can improve our understanding of the complexity of a business model's components and their interdependence by becoming a management

This article is part of the Topical Collection on Sustainability in business models in the network economy

Responsible Editor: Marek Jabłoński

Anna Ujwary-Gil

ujwary@inepan.waw.pl

Natalia Regina Potoczek

npotoczek@inepan.waw.pl

1 Institute of Economics, Polish Academy of Sciences, Nowy Świat 72, 00-330 Warsaw, Poland and decision-making tool. According to the authors' knowledge, organizational network analysis techniques were used for the first time to identify the components of the virtual reality company's business model, based on determined cause-effect relationships (incoming/outgoing) dealing with existing interdependencies between components. In the approach proposed here, nodes are interpreted as key components of the business model and edges as interactions between them, which allows the analysis of system dynamics using network measures.

Virtual reality is based on information technology and requires the use of advanced digital competences. Thus, the business model of the virtual reality company is focused on a very high level of usability and solving customer problems. Digital competences mean the conscious and creative use of information and communication technologies for purposes related to work, study, and an active participation in a social life. According to the European Commission's European Digital Competence Framework for Citizens (DigComp), ${ }^{1}$ digital

\footnotetext{
${ }^{1}$ See https://ec.europa.eu/jrc/digcomp.
} 
competences are divided into five areas 1) information and data literacy 2) communication and collaboration 3) digital content creation 4) security 5) and problem solving, including technical problems; identifying technological needs and reactions; creatively using digital technologies; and identifying digital competence gaps. Digital competences understood in this way are becoming crucial, especially in virtual reality companies, creating not so much a socio-technical system, but rather a socio-digital one in which the information system, through digital technology, allows dispersed economic and social entities not only to exchange but also to integrate resources leading to digital value co-creation (Blaschke et al. 2019). To know and understand this phenomenon, the sophisticated organizational network analysis techniques seem to be beneficial as well.

\section{Related work}

The business model has been analyzed in various contexts. One of the most popular is business model innovation (BMI) (e.g., Freiling 2015). Foss and Saebi (2017) conducted an invaluable subject literature study, in which they analyzed 150 papers on BMI, thus identifying four research gaps in this area, connected with construct definition and dimensionalization; congruence and identifying antecedents and outcomes; contingency and moderating variables; and boundary conditions. Hacklin et al. (2018) combine research on business models at an enterprise level with research at the sector level, focusing on value migration in order to examine the patterns of innovation in a business model. Linder and Williander (2017) show that cyclical innovation in a business model poses serious challenges to entrepreneurs proactively trying to reduce uncertainty. They are based on regeneration and reuse; they ensure considerable savings and radically limit the environmental impact. As demonstrated in the research conducted by Sorescu (2017), the most successful startups of recent years, such as Airbnb or Uber, have been stimulated by BMI rather than by product innovations. The author uses the growing flow of research on business models in the literature on strategy, to propose ways in which companies can use this information, including information networks and big data, in order to introduce innovations to their current business models or to develop new ones.

Other interesting presentations can be found in the concept of freemium business models (Günzel-Jensen and Holm 2015), social ventures (Jokela and Elo 2015), or the role of emotions (Straker and Wrigley 2015) in the development of BMI. In their research, Trapp et al. (2017) presented BMI as a process of integrating the new logic of conducting business activities with a well-established company to improve profitability or take advantage of new business opportunities. Exceptional BMI research has recently been conducted by Weking et al. (2019), who developed the taxonomy (five archetypal patterns) of blockchain business models to explore the impact of blockchain technology on existing and new business models.

Another research area is dedicated to creating and/or proposing value on the basis of a selected business model (e.g., Amit and Zott 2001, 2012; Fallahi et al. 2017; Sanchez and Ricart 2010). This approach is closely connected with the concept of a business model divided into different components (dimensionalism), which together (through synergy and combinations) contribute to creating value. A component of the business model has an entirely different meaning than a component in the network analysis. In business models, components are treated as elements of the model. Those can be, for instance, a value proposition, a financial model, client segments, and many others that become the object of management. In the network analysis, on the other hand, a component is considered to be the minimum requirement for a coherent subgroup. Here a component consists of a subgroup of individuals, where all individuals are interconnected by means of at least one path (see Prell, 2012). In this paper, the word "component" will be used only in the business model context.

Another research was conducted by Priem et al. (2017), who perceive creating value for consumers as a condition for gaining value, constituting a foundation on which research on demand is based, and which is a primary element of nearly every business model. Other scientists emphasize the ties between the business model and the intellectual capital (Beattie and Smith, 2013; Ujwary-Gil, 2017), which perform identical functions oriented at value creation.

These two areas oriented at business model innovation and value creation have been well analyzed in the literature, whose most prominent works on this subject have been mentioned above. In the next part of the paper, the concept of the sustainable business model is presented more broadly from the perspective of the network of relations between components constituting the business model. The network approach (including the dynamic approach) to the analysis of a business model remains a new area of exploration. The few publications devoted to this issue, concern a slightly different presentation of the network than the approach proposed by the authors of this paper. We can list here: system innovations in sustainable development included in business networks and models based on values (Breuer and Lüdeke-Freund 2016); network business models providing visibility (traceability) of the delivery chain (Dellyana et al. 2016; Suherman and Simatupang 2017); distribution networks (Li et al. 2018); and internal logic of the service providers in achieving a successful project coalition (Rajakallio et al. 2017).

\section{Research problem, objectives and questions}

The above studies concern a diversified approach to the research on business models. Based on the literature review, it 
can be concluded that existing dynamic, network, and resource-based approaches are applied to the business model analysis. There is, however, no broader research on how a network approach can be used to measure and understand the dynamics of interactions and interdependence between the components of a business model. This is a network study of the business model from an intra-organizational perspective. The main research problem is the assumption that a business model consists of components with different positions, influence, and value in the network. If so, the value of network metrics changes after removing a central node or nodes from the network (business model), which affects the change of a business model from the perspective of interaction and interdependence of its components.

The paper aims to present the possibilities of studying a virtual reality company's business model using network analysis from a dynamic and resource perspective. For exemplification, selected network metrics are presented to show the possibilities and benefits of their use in analyzing the business model. The component presentation of the business model is used to demonstrate interactions between resources, and measures their influence and position in the network using centrality metrics. Thus, the dynamic presentation concerns the business model analyzed from the view of a network of relations. In this way, it is possible to assess the sustainability of the business model in a situation of simulated changes to its components. The simulation consists of removing the key node, or an element of the business model. In the paper, the terms 'component', 'element,' or 'attribute' (of a business model) and a (network) 'node' are used interchangeably. Initial results show the most prominent (influential) components of the analyzed business model, changes in centrality measures, as well as its network (business model) resistance to change.

The presented topic of relations between a virtual reality company's business model components in the network approach and the examination of the resistance to change of the business model is becoming a research area. Another area of research is the analysis of the ties and positions of the business model components, paying particular attention to the most influential nodes in the network. The core research questions, based on the research problem statement presented above, were as follows:

RQ 1) Which components of a business model have the most influential position?

Answering this question aims at identifying key elements of the business model based on 19 attributes expressing the specifics of the company being studied. It is assumed that the largest changes in the business model, i.e., those whose effects are perceptible to the entire business model, result from changes in the configuration of connections of each key element with all other elements. Human resource is the easiest example to illustrate. Excluding some contractors from the business model may make the project impossible to implement due to their specific competences or relationships with other entities.

RQ 2) How does the size of network measures change as a result of removing a central node or other nodes of a business model?

By analyzing the removal of particular elements of the business model, it is possible to determine the value of the centrality degree of the remaining nodes. The configurations resulting from the removal of the selected node should become the basis for the analysis of alternative configurations and their potential from the perspective of set business goals. If it is possible to identify key elements of the model, it is also possible to predict changes based on simulated model reconfigurations. However, it should be remembered that the starting point for performing simulations in the area of centrality of individual nodes, and their impact on the business model, is a correctly identified matrix of influences for all identified elements.

RQ 3) How resistant to change is a business model, taking into account the change in network relationships between the various components of a business model?

The information obtained during the simulation of nodes in the network, i.e., the change of components in the model, provides valuable information not only about the conditions of the business model but also about the need to optimize the business venture. The resistance to change of the business model is reflected not only through the participation of individual components of the business model but also through their proper use and allocation. Network analysis allows one to take a closer look at the share of individual elements in different configurations, and to assess their actual value for the business model.

The paper is composed of the following sections: the theoretical background, where we present the resource approach to defining business models, and the network and dynamic analysis as a key tool in analyzing a business model from the perspective of the network of ties between its components. The literature part concludes with considerations of the sustainable business model. Next, the structured research methodology section provides justification for the selected research approach and explains the data collection process. Finally, the paper offers the findings and a discussion of the presented results, implications for theory and practice, limitations, and directions for further research, as well as a conclusion. 


\section{Theoretical background}

\section{Resource approach to the business model}

In the literature on business models, the resource approach has always played a prominent role. This is mainly due to the perception of a business model as a set of its components (elements, mostly resources), whose interaction (between them) determines the final result - value creation or proposition. The leading representatives of the resource approach are Barney (1991, 2001) and Penrose (1995). They place resources and skills at the center of researchers' interest. They attempt, based on resources (tangible and intangible, as well as the skills of using them), to recognize the competitiveness of enterprises operating in the market. The internal resources of an enterprise are the primary source of value creation, where it is necessary to control critical assets and skills in order to maintain a competitive advantage (Sanchez and Ricart 2010). Barney (1991) lists the following resources: assets, skills, organizational processes, enterprise attributes, information, and knowledge.

Penrose (1995) perceived a company as a sophisticated package of heterogeneous and production resources, covering interactions between material and human resources. She has contributed significantly to the differentiation between resources and activities. Resources constitute a potential for action, which may generate various flows of services or activities. Without subordinating particular resources, both tangible and intangible, to actions, a service will not be rendered. The identified resources and actions offer a starting point for an analysis of the interdependencies between them. These activities usually concern the use of resources, which has not been emphasized sufficiently in the resource approach. The resource approach to the business model analysis can be found in Hedman and Kalling (2003). Here, company resources include project skills, relations with suppliers, supply networks, and cultural factors related to leadership and active involvement. The business model is mostly perceived through the prism of creating value for clients and delivering such value (Morris et al. 2005; Zott et al. 2011). According to Johnson et al. (2008), a business model is a value proposition for a client, a profit formula, and key resources and processes in the context of creating and delivering value to clients and organizations.

Osterwalder and Pigneur (2010), whose names cannot be omitted here, popularized the business model in practice. In their approach, the business model treats resources holistically - it organizes mainly resources and activities, which determine value creation. At the heart of this model is a value proposition, resulting from the interactions taking place between key resources, activities, groups of clients, distribution channels, relations with customers, partners, sources of revenues and costs. A competitive advantage is revealed through better performance of activities within the internal value chain, better coordination between these activities, better management at the meeting point of an enterprise and other entities in the value network, namely: suppliers, partners, distribution channels, various coalitions, which go beyond the traditional view of enterprise resources (Nair et al. 2012). The analysis of ties between business model components is the subject of the presented study.

\section{Dynamic and network approach to the business model}

Resources configured in a particular business model may determine an organization's strength and its competitive advantage. By measuring and monitoring variables describing networks of resources and their configuration, we can find out where the value is created or destroyed in an organization. This also requires measuring created value and learning the dynamics of changes resulting from such a configuration of the network. It seems justified then to relate to the dynamic presentation of company growth according to Penrose (1995), based on the identification of its key components which help to explain the company growth process by theorizing about the dynamics between these components, as pointed out also by Demil and Lecocq (2010).

One of the first dynamic presentations of a business model can be found at Zott and Amit (2010), who perceive it as a system of activity composed of two parameters: architecture and source of value creation. The system of activity comprises the choice of actions; the structure determines how activities are interrelated, while management indicates who will perform an activity. The use of resources in action gives them a dynamic character, just as the diagnosis of the relations network and the configuration of ties. Similarly, the business model is captured by Wirtz et al. (2016). It is a simplified and aggregated way of presenting the company's activities. Here, a business model describes how transferable information, products and/or services are created using the company's value-added component. In addition to the value creation architecture, strategic components related to clients and markets are taken into account to achieve the goal of competitive advantage. The authors also draw attention to the dynamic aspect of the business model and its adjustment in time.

All the above elements constitute a specific infrastructure, based on which, network actors (understood here as organization employees) gain knowledge, perform tasks or use resources, and intertwine in a complicated network of mutual influences (Blackler 1993). The choice of a dynamic approach to resources allows to look at the resource network as a structure of activities and to present resources in a specific structure of ties. These dynamics are related to the view of resources through the prism of relations, ties and configuration, which transform them into actions. 
The dynamic and network approach focuses on changing the business model and its components. A company's ability to create value through a network of ties and changes to components, seems to be the central point in considerations over the building and continuous development of the dynamic business model. There is no single definition or unanimous agreement as to the classification of the exposed components of a business model. However, in order to understand how value is created for a client, it is vital to identify the elements of a business model and the relations between them. The dynamic approach shows that different sets and combinations of components and their attributes, also affect the differentiation of an organization's ability to deliver value.

The dynamic aspect of the network analysis, analyzed in a broader, organizational context, was already noticed by Tichy et al. (1979). They pointed to the need to examine the static and dynamic aspects of an organization and its ties between social objects over time. The dynamic aspect of the network refers to the relations and influence exerted between network elements (nodes). In the paper, the business model is, therefore, a network of ties between its components. It consists of many types of nodes and an unlimited combination of relations existing between them.

An essential element in the dynamic presentation of the network is the simulation of changes and the network modeling by adding or removing nodes and/or relations, as well as changing relations and their power (Tsvetovat and Carley 2004). Some changes, which may affect the network structure concern, for example, fluctuation of people, changes in mission statement, technology, use of resources, or creating resources. A potential change in any network node may lead to changes in other nodes.

In order to perform a simulation in which we lose particular nodes in the network, we can calculate the changes in the size of selected network measures after a particular node has been lost (see Everton 2012). The removal of a node can be intentional or random, with any numbers of repetitions, which enable to assess whether the removed node or nodes affect the network. Network interventions are based on the theory of innovation diffusion (Rogers 2003), which explains how new ideas and practices distributed inside and between societies are generated. The choice of a node to simulate changes in the network is based on choosing the most prominent nodes, depending on the applied centrality measure (Borgatti et al. 2018). When selecting nodes, it is helpful to determine the key node using specialist software (e.g., Organizational Risk Analyzer; Ucinet). It may be beneficial to add network nodes selectively, depending on network features, such as network coherence. New nodes and relations should be added to the network to eliminate loosely connected groups, knowledge, or resource gaps. Removing a node occupying a critical position in the network allows to examine changes to the network structure (Valente 2010).

\section{Sustainable business model}

The sustainable business model (SBM) has various meanings in the subject literature. In the majority of publications, it is perceived as a tool for coordinating technological and social innovations, or as a balanced system covering a wide range of stakeholders, environment, and society (e.g., Bocken et al. 2014; Yip and Bocken 2018). The SBM concept is often used incoherently, referring to the balanced finance of a business model or, more frequently, a contribution to the sustainable development of the natural environment and society (c.f., Lüdeke-Freund and Dembek 2017). The connection between a sustainable business model and value creation in various stages of a company life cycle can be found in Jablonski and Jablonski (2016). The authors emphasize the differences in business models in the context of company life cycles and sustainable development criteria. They perceive a sustainable business model as based on balancing various areas of activity in the form of constructive comparisons.

In this paper, "sustainable" shall refer to the organizational ability to create value through the business model and its components, which determine the competitive advantage and resistance to change of the model, at least in the short period of time and its adaptation (see Balboni and Bortoluzzi 2015). We need to understand how to constantly develop, allocate, exploit and combine an organization's resources to update, renew, and create organizational skills within the business model. Apparently, this is not only about gathering resources but how these resources are transformed into a process, product, reputation, and brand, creating value which is transferred into financial returns for stakeholders (Peppard and Rylander 2001; Schiuma 2009).

Morris et al. (2005) perceive a unique combination of resources within a business model, where every component affects and is affected by other components, as an opportunity to create values and higher returns for an enterprise. Peppard and Rylander (2001) believe that value may be generated by combining and using resources. The introduction of new components may change the dynamics of the existing ones. Moreover, these dynamics determines the sustainability of a business model and helps us understand to what extent changes in the business model components affect the resistance to change of the whole business model and its structure, understood as a network of relations between its components.

\section{Methodology and research approach}

\section{Network approach}

The research approach is based on organizational network analysis techniques. The organizational network analysis 
(see Merrill et al. 2008) can be applied here, since the business model is composed not only of social (human) actors, as it is in the social network analysis where a human is the basis of relations, but also of non-human actors. This human and non-human approach to the analysis of a system (business model) is particularly visible in the actor-network theory (Alcadipani and Hassard 2010), where human and nonhuman actors are treated equally and can influence the socio-technical system and future technological development. Here, the business model is of a non-human type, even if people constitute its prominent component, and the business model itself is a part of an organization. We use a binary $(0 ; 1)$, one-mode, adjacency matrix as a mathematized network conceptualization (Borgatti et al. 2018) in which rows and columns represent nodes, and the position in row $i$ and column $j$ represents the connection from $i$ to $j$. If aij $=1$, then there is a connection from $\mathrm{i}$ to $\mathrm{j}$, otherwise aij $=0$. We adopt network measures (see Table 1) that are based mainly on binary matrices, as interpreted by Altman et al. (2017). The matrix is directed, which means that xij may or may not be equal to xji.

In the network research, the following measures were used: the total-degree centrality (TDC), including out- and in-degree centralities, network density, and the Immediate Impact Report, which are incorporated in the Organizational Risk Analyzer software, version ORA-NetScenes 3.0.9.9.38 (Carley et al. 2018), to analyze the network position, influence, and resistance to change of the presented business model. Network density is a measure of network connection. It is defined by the possible number of relationships. This is a value that varies between 0 and 1 . When the density is close to 1 , the network is very dense; there are all possible relationships in the network. When dealing with directed relations, the maximum possible number of dyads is taken into account.
The classic network density determines the number of existing links in a given network, divided by the number of possible links (Freeman 1978). Density compares existing ties to all possible connections in the network (business model). It reflects the degree of interdependence and consistency between the nodes of a business model. The higher the density, the more complete the network is or the degree of its crosslinking is. In practice, the loss of a critical node or nodes can have major business consequences that require attention from decision-makers.

In turn, the total-degree centrality is the normalized sum of its rows and columns. It determines the number of direct incoming and outgoing relations of the analyzed network node and the potential to influence other nodes (Wasserman and Faust 1994). The centrality degree of a node with numerous ties is perceived as significant in a given network or having a high impact on other nodes in the network. The in-degree centrality of a node is determined by the number of incoming relations received from other nodes and the influence of direct connections, interpreted as the possibility of being subject to direct influences. The more incoming connections, the more influenced-by-others the node will be in the network. Outdegree centrality defines the number of outgoing relations that a given node transmits to other nodes and the influence of direct connections, interpreted as the possibility of exerting a direct influence on other nodes. The more outgoing connections, the more influential the node will be in the network.

The Immediate Impact Report computes the key elements of the network (business model) and then isolates them individually to determine the effect on measured values. Immediate impact testing allows to identify and isolate key network elements (business model) to determine changes in the centrality of nodes after the removal of a selected node and

Table 1 Network measures

\begin{tabular}{|c|c|c|}
\hline Measure & Formula & Description \\
\hline $\begin{array}{l}\text { Density } \\
\text { (network level) }\end{array}$ & $\begin{array}{l}\text { Let } A \text { be the binary input network with } m \text { rows and } n \text { columns. } \\
\text { The density of network } A=\operatorname{sum}(A) / m^{*} n \text {. } \\
\text { If } A \text { is one-mode and does not allow self-loops, } \\
\text { then the density }=\operatorname{sum}(A) / n^{*}(n-1)\end{array}$ & $\begin{array}{l}\text { The ratio of the number of links versus } \\
\text { the maximum possible links for a network. }\end{array}$ \\
\hline $\begin{array}{l}\text { Total-degree centrality } \\
\text { (node level) }\end{array}$ & $\begin{array}{l}\text { Let } A \text { be the input network with } \mathrm{N} \text { nodes and max. } \\
\text { Link value } \mathrm{V} \text {. } \\
\text { Total-degree centrality for node } \\
\quad \mathrm{i}=(\operatorname{sum}(\mathrm{A}(\mathrm{i}, \mathrm{i}))+\operatorname{sum}(\mathrm{A}(:, \mathrm{i}))-\mathrm{A}(\mathrm{i}, \mathrm{i})) / 2^{*} \mathrm{~V}^{*}(\mathrm{~N}-1)\end{array}$ & $\begin{array}{l}\text { Total-degree centrality of a node is the normalized } \\
\text { sum of its in-degree and out-degree. }\end{array}$ \\
\hline $\begin{array}{l}\text { Out-degree centrality } \\
\text { (node level) }\end{array}$ & $\begin{array}{l}\text { Let } \mathrm{A} \text { be the input network with maximum link value } \mathrm{V} \\
\text { Out-degree centrality = row } \operatorname{sum}(\mathrm{A}) / \mathrm{V}^{*} \operatorname{cols}(\mathrm{A}) \\
\text { Note: the network } \mathrm{A} \text { is one-mode and not using the diagonal, } \\
\text { then the measure is normalized by } \mathrm{V}^{*}(\operatorname{cols}(\mathrm{A})-1)\end{array}$ & $\begin{array}{l}\text { The number of links emanating from a node normalized } \\
\text { by the maximum number of such links }\end{array}$ \\
\hline $\begin{array}{l}\text { In-degree centrality } \\
\text { (node level) }\end{array}$ & $\begin{array}{l}\text { Let } \mathrm{A} \text { be the input network with maximum link value } \mathrm{V} \\
\text { In-degree centrality = column } \operatorname{sum}(\mathrm{A}) / \mathrm{V}^{*} \text { rows(A) } \\
\text { Note: the network } \mathrm{A} \text { is one-mode and not using the diagonal, } \\
\text { then the measure is normalized by } \mathrm{V}^{*}(\operatorname{rows}(\mathrm{A})-1)\end{array}$ & $\begin{array}{l}\text { The number of links directed into a node normalized } \\
\text { by the maximum number of such links. }\end{array}$ \\
\hline
\end{tabular}

Source: based on Altman et al. (2017) 
to assess the influence of the network stability. Change analysis allows the user to select specific nodes to add or remove, and to select individual links to add, remove or modify values. The report then shows the differences in values between the original and modified network at both the node level and the network measures. For example, analyzing changes may allow removing one or more nodes identified in another report (Key Entities) as part of a network degradation assessment if those nodes are no longer in the network. This is a more precise version of an immediate impact analysis with a wider range of options than random node removal (see more Carley et al. 2018). Table 4, in the section that discusses the presented results, shows the differences in values between the original and modified networks at both the node and network measure levels.

\section{Data collection process}

The choice of these specific components of the business model was determined by the research material obtained within the EU project titled "Transforming SMEs in Creative Sectors through Business Model Innovations (Reinvent)," implemented within the 7th Framework Program - People in 20132016. Data collection was based on an organized workshop. Components were first identified during the workshop, similarly to Kaplan and Norton (1992) key success factors. During the workshop, a group of five people identified the key components of the business model of the virtual reality company and the impact of the components on each other (see Table 2). The choice and assessment of components' attributes were made by a representative of the board of the analyzed company (Poland), a company IT specialist (Poland), a Reinvent project researcher (Iceland), a Reinvent project researcher (Denmark) and one of the authors (Reinvent project researcher, Poland).

Each of the participants received two questions: 1) What are the attributes of the company's business model components? 2) Is there a strong influence of this component on another component listed in the columns? The responses were binary $(0-$ there is no strong influence, 1 - there is a strong influence). Thus, the question form allowed analyzing the impact of each of the attributes on the other ones listed in the one-mode matrix, as shown in Table 2 . The analysis was made according to individual rows of the matrix.

To document the results, flipcharts were used during the workshop (see also Otto and Jarke 2019) and a dedicated excel file with a scatter plot. The subsequent analysis of relationships and interdependencies was complex and supported by selected advanced network techniques, which are presented in Table 1. The choice of components was subordinated to the general framework of Osterwalder and Pigneur (2010) (nine general components, like key partners; key resources; key activities; value proposition; customer relations; customer segments; distribution channels; cost sources; revenue sources). The 19 components' attributes identified (like business; academy; local government units;

Table 2 Components of the business model of the virtual reality company

\begin{tabular}{|c|c|c|c|c|c|c|c|c|c|c|c|c|c|c|c|c|c|c|c|c|c|}
\hline No & Business model compo & nents & 1 & 2 & 3 & 4 & 5 & 6 & 7 & 8 & 9 & 10 & 11 & 12 & 13 & 14 & 15 & 16 & 17 & 18 & 19 \\
\hline 1 & Key partners & business & 0 & 0 & 0 & 1 & 1 & 1 & 0 & 0 & 1 & 0 & 0 & 0 & 1 & 0 & 1 & 0 & 1 & 0 & 0 \\
\hline 2 & & academy & 0 & 0 & 0 & 1 & 1 & 0 & 0 & 0 & 0 & 0 & 0 & 0 & 1 & 0 & 0 & 1 & 1 & 0 & 0 \\
\hline 3 & & local government units & 1 & 1 & 0 & 1 & 0 & 0 & 0 & 0 & 0 & 0 & 0 & 0 & 0 & 0 & 1 & 0 & 0 & 0 & 0 \\
\hline 4 & Key resources & people & 1 & 0 & 0 & 0 & 1 & 1 & 1 & 1 & 1 & 1 & 1 & 1 & 1 & 1 & 1 & 1 & 1 & 1 & 1 \\
\hline 5 & & technology and infrastructure & 0 & 1 & 0 & 1 & 0 & 1 & 1 & 1 & 1 & 1 & 1 & 0 & 0 & 0 & 1 & 0 & 0 & 1 & 1 \\
\hline 6 & & finance & 0 & 0 & 0 & 1 & 1 & 0 & 1 & 1 & 1 & 1 & 1 & 0 & 0 & 1 & 1 & 0 & 1 & 1 & 1 \\
\hline 7 & Key activities & visualization & 1 & 1 & 1 & 0 & 0 & 0 & 0 & 1 & 1 & 1 & 1 & 0 & 0 & 0 & 1 & 0 & 0 & 1 & 1 \\
\hline 8 & & problem solving & 1 & 1 & 1 & 1 & 1 & 1 & 1 & 0 & 1 & 1 & 1 & 0 & 1 & 1 & 1 & 0 & 0 & 1 & 1 \\
\hline 9 & & trainings & 0 & 0 & 0 & 1 & 0 & 0 & 1 & 1 & 0 & 1 & 1 & 0 & 0 & 0 & 0 & 0 & 0 & 0 & 0 \\
\hline 10 & Value proposition & simulations & 1 & 1 & 1 & 0 & 1 & 0 & 1 & 1 & 1 & 0 & 1 & 0 & 0 & 0 & 1 & 0 & 0 & 1 & 1 \\
\hline 11 & & "wow" effect & 1 & 1 & 1 & 1 & 0 & 1 & 1 & 1 & 1 & 1 & 0 & 0 & 0 & 1 & 1 & 0 & 0 & 1 & 1 \\
\hline 12 & & after-sales service & 1 & 1 & 1 & 0 & 0 & 1 & 0 & 1 & 0 & 0 & 0 & 0 & 1 & 1 & 1 & 0 & 1 & 0 & 0 \\
\hline 13 & Customer relations & positive image & 1 & 1 & 1 & 1 & 0 & 1 & 0 & 1 & 1 & 0 & 0 & 0 & 0 & 1 & 1 & 1 & 1 & 0 & 0 \\
\hline 14 & & customer service & 1 & 1 & 1 & 0 & 0 & 1 & 0 & 0 & 1 & 1 & 0 & 1 & 1 & 0 & 1 & 1 & 1 & 0 & 0 \\
\hline 15 & Customer segments & international markets & 0 & 0 & 0 & 1 & 1 & 1 & 1 & 1 & 1 & 1 & 1 & 0 & 1 & 0 & 0 & 0 & 1 & 0 & 0 \\
\hline 16 & Distribution channels & personal contacts & 1 & 1 & 1 & 1 & 0 & 1 & 0 & 1 & 1 & 0 & 0 & 1 & 1 & 1 & 1 & 0 & 1 & 0 & 0 \\
\hline 17 & & networking & 1 & 1 & 1 & 1 & 0 & 1 & 0 & 1 & 1 & 0 & 0 & 0 & 1 & 0 & 1 & 1 & 0 & 0 & 0 \\
\hline 18 & Cost sources & presentations/exhibitions & 1 & 1 & 1 & 0 & 1 & 1 & 1 & 1 & 1 & 1 & 1 & 0 & 1 & 0 & 1 & 1 & 1 & 0 & 0 \\
\hline 19 & Revenue sources & virtual reality projects & 1 & 1 & 1 & 1 & 1 & 1 & 1 & 1 & 1 & 1 & 1 & 0 & 1 & 0 & 1 & 0 & 0 & 0 & 0 \\
\hline
\end{tabular}


human capital; technology and infrastructure; finance; visualization; problem-solving; training; simulations; "wow" effect; after-sales service; positive image; customer service; international markets; personal contacts; networking; presentations/ exhibitions; virtual reality projects) had to match the specificity of the virtual reality company.

The network was created on the basis of a one-mode matrix in which a strong influence of particular components on each other was marked (Table 2). Examples of network visualizations are presented in the Findings section of the paper.

\section{A virtual reality company}

The object of our study is a business model of a company operating in the sector of new technologies - virtual reality. The company was established in Poland in 2007 and it operates in the area of interactive 3D graphics. It offers fully interactive, three-dimensional visualizations and presentations of any models or objects, such as buildings, structures, appliances, production lines, transport means, etc. The company's offer includes complex application and equipment solutions, and is directed at businesses and territorial self-government, government agencies, and science centers. The company offers state-of-the-art technology, which allows users to replicate the real world entirely in virtual reality. Thanks to this, it can be applied to many areas of life, for example, sales, marketing and advertising, education, industrial design, planning and optimization, culture, and entertainment. The technology the company offers significantly speeds up the process of designing and verifying constructions, as well as testing and checking the functionalities of the modeled buildings and structures. It is also possible to create software to conduct training using the equipment or technology lines before they are actually produced. The solutions proposed by the company may also be used for product presentations and exhibitions, as well as on the Internet as tools supporting Internet location and configuration devices. The applications and equipment solutions created by the company allow one, for example, to reconstruct historical sites, industrial appliances, or to view museum collections. They can also be used when making inventories of buildings, as instruction or service manuals, and simulators. The company used to employ thirty graphic designers, designers, and programmers - mainly scientists and students of the nearby university of technology.

\section{Findings of the study}

The business model of the virtual reality company consists of nine main components within which key attributes have been identified. From the description of the company's activity, we can see that the company's key partners are broadly understood as businesses (registered companies), local government units, and academic centers (universities). The key resource the company possesses is the young, qualified staff - talented IT specialists and graphic designers. Moreover, the company also prides itself on having state-of-the-art technology and infrastructure as well as financial resources that determine its financial liquidity. The main areas of activity include virtual visualization and modeling virtual reality, solving the client's problems, and training dedicated to customers and their products and services. Each business model should be based on good relations with clients, as they determine the positive image of the company. The company concentrates mainly on international markets, in particular, in Asian and western (USA) markets, but they do also render services for domestic clients. Distribution takes place mainly on the basis of the personal relations developed by the company owners and project directors, and the networking of the staff it employs. The chief source of income is the implemented projects in virtual reality, whereas costs are generated by the necessity to prepare presentations, exhibitions, and demonstration projects, before they become saleable projects. The most important element of the presented business model is the value proposition, whose source lies in simulations (of problems and solutions) dedicated to meet the clients' needs and the "wow" effect, that is making sure the client is fascinated with and admires the functionality and attractiveness of the implemented projects, as well as providing clients with a professional after-sales service, vital for this type of activity based on IT solutions.

Table 3 presents the results of the total centrality, including in- and out-degree centrality. Metrics determine the position of particular components of the business model in the network of their relations. Font styles in Tables 3 and 4 mean that if the node of interest has a higher than normal value (greater than 1 standard deviation(s) above the mean), the row is italic. The row is regular if the node is within 1 standard deviation of the mean. Finally, the row is bold if the node has a lower than normal value (less than one standard deviation(s) below the mean).

Figs. 1 and 2 depict the network of ties between business model components before and after removing the selected node (people). The selected node is removed from the network and the effects are measured by comparing the values of key metrics (density and total-degree centrality) before and after its removal. The results are shown graphically in terms of the portion of the network "near" the node that is removed and is statistically based on the entire network. The portion of the network that is "near" the node that is removed is defined as all known nodes of the selected node class within a path length of 2 from the target node. For example, if the node class is a business model component and the target is people, then the displayed network contains all other components that are directly connected to the people component or are directly connected to another that is directly connected to people.

It is worth assessing here the impact exerted by removing the selected node people on other nodes and the resistance to 


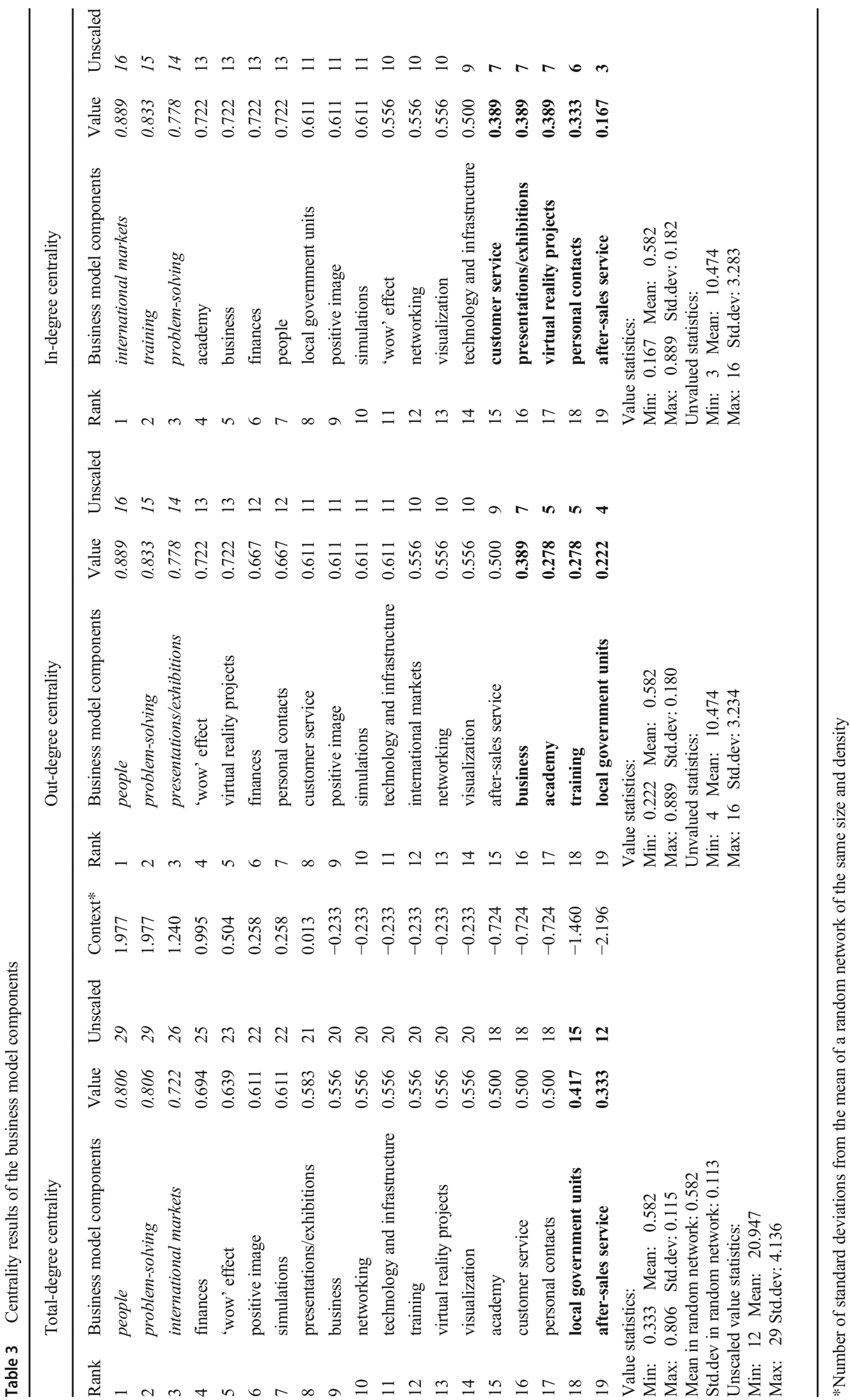




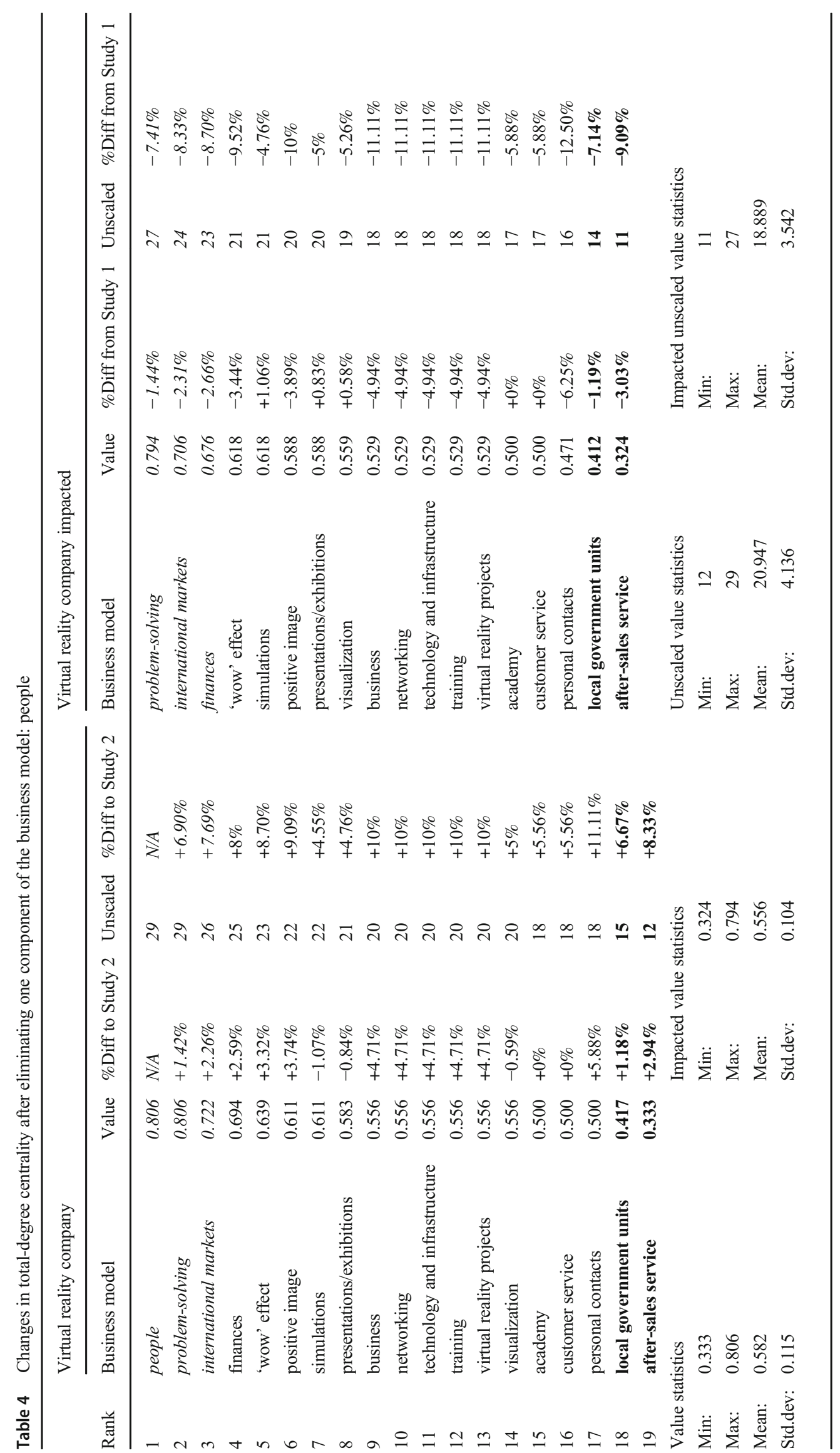




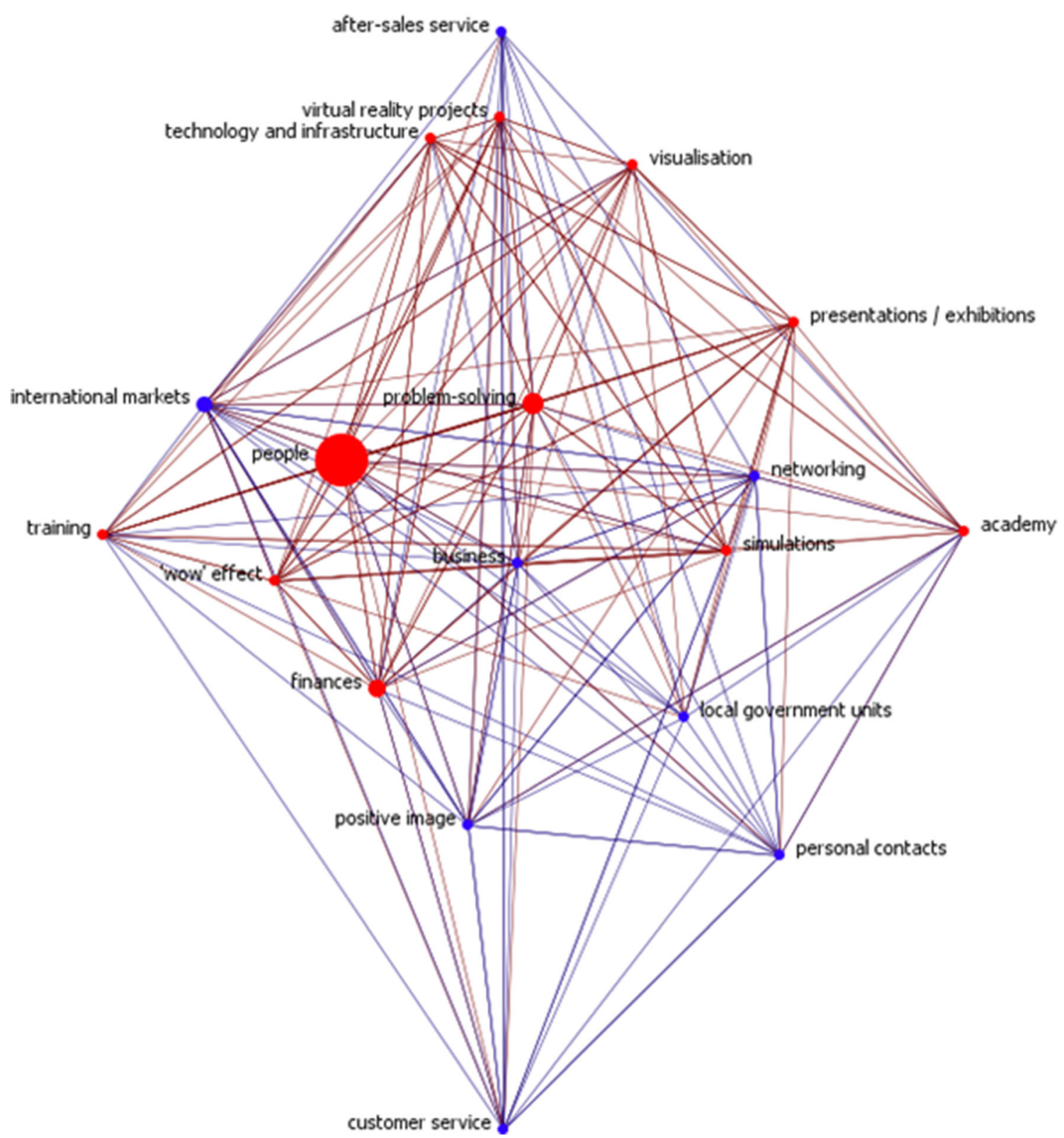

Fig. 1 Network of business model components before the change

change of the network (business model), measured with the network density indicator. The selected component of the business model was removed from the network, and the effects are measured by comparing the values of the total-degree centrality before and after removing it. The results are presented in Table 4.

\section{Discussion of the presented results}

The total-degree centrality measure presents the ranking of components, from the most to the least prominent ones in the network, containing both incoming and outgoing relations. The value of this measure ranges from 0.806 (the most central node) to 0.333 (the least central node). The results presented in Table 3 show that the matrix is not symmetrical; there is no mutuality of relations between each component. The outdegree centrality results show components that affect other components, mostly due to the number of outgoing relations. In-degree centrality demonstrates there are some business model components that do not exert a strong impact on others; instead, they are affected by them. The rank of components in the out-degree and in-degree columns differ, which also demonstrates the varied force of impact that particular components exert on each other. The centrality measures indicate the key network nodes (business model components). Based on this, we selected the people component for the initial simulation of the loss of a network node. Figures 1 and 2 depict the network 


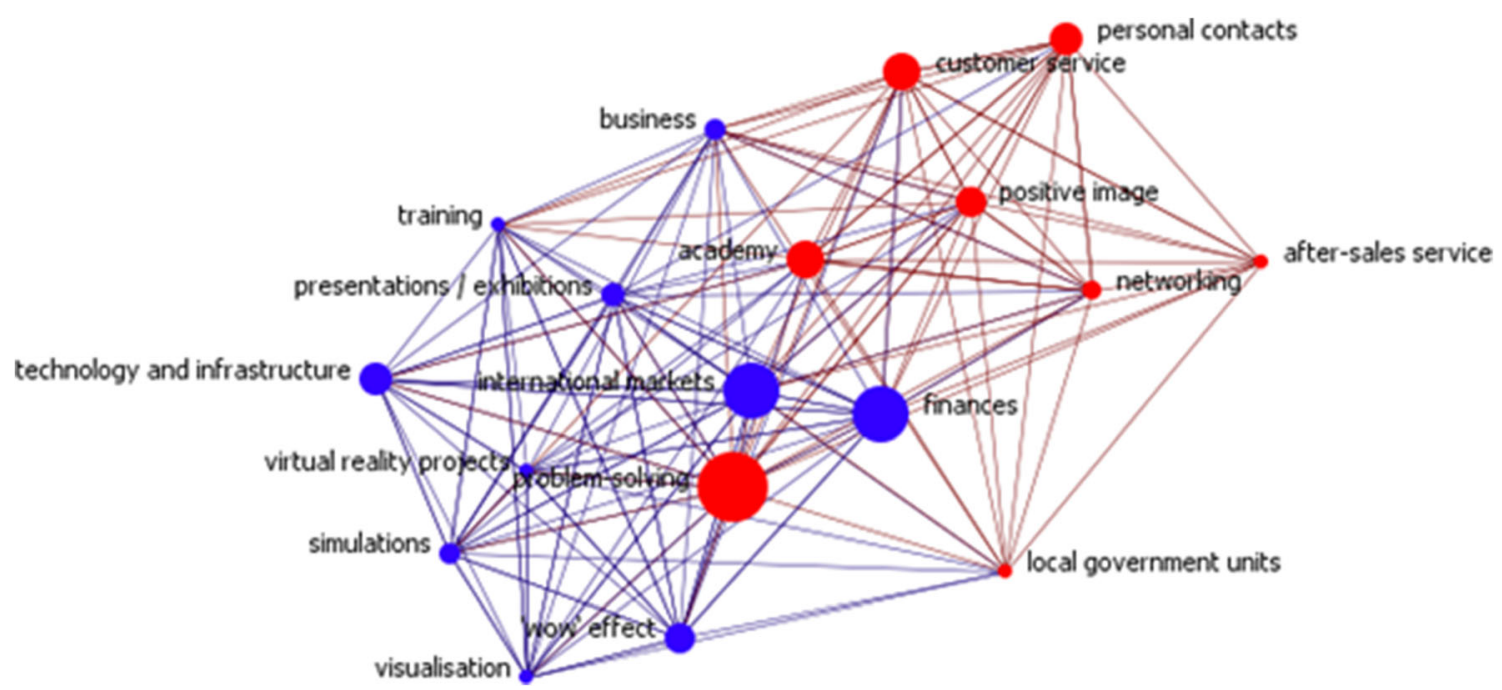

Fig. 2 Network of business model components after the change

of relations of the business model before and after losing the key node. The network density measure decreased from 0.582 (199 links) to 0.555 (170 links). It should be noted that, so far, there has not been sufficient research on a greater number of cases to generalize about the changes of particular components when analyzing the business model (using density and centrality metrics). The simulation showed that the density remained at a relatively high level.

Earlier research (c.f., Kasztler and Leitner 2009) concerned the use of a social network analysis to identify the driving factors that allow control of the development of intellectual capital based on closeness and in-degree centrality. Compared with traditional methods such as strategic maps, Kasztler and Leitner (2009) identified possible relationships between factors considered necessary for measuring and managing intellectual capital. Based on the concepts of relationship networks, Pike et al. (2005) interpreted nodes as resources and edges as transformations of intangible resources. Studying R\&D organizations, they analyzed which factors influence other factors and which are affected by other factors, remaining either unused or excessively used, which may indicate the ineffectiveness of the organization's results. The starting point for using network analysis was to identify the nodes of the tested system. Ujwary-Gil (2020) used organizational network analysis to analyze the intersections between intangible resources constituting the business processes of an IT company, to understand the complexity of the sociotechnical system and its efficiency. The centrality measures used in our study allow us to identify the central position of particular components of the business model in the network. As we can see, people (key resources), problem-solving (value proposition), international markets (client segment), and presentations/exhibitions (cost structure) have prominent positions in the network, well above the average, becoming the key areas of management control and decisions. In order to analyze the impact zones (Table 4), we chose the people component due to its most prominent position in the network (total-degree centrality and out-degree centrality). Around each node, a particular sphere of influence originates, consisting of various class nodes, which a particular node influences or is influenced by. In a standard social network, which contains connections between network actors and can be intentional, the impact sphere concerns the ego network of a given actor. Here, the ego network of the central node (people) covers direct connections with nodes in the network and connections between them. The in-coming connections allow one to determine which nodes affect the ego-node (people). The outgoing connections, on the other hand, indicate nodes that the ego (people) affects directly. The network analysis shows that the people component of the business model directly affects in total 16 other components, except for academy and local government units (key partners). The people node, on the other hand, is affected in total by 13 other components, except for visualization (key activities), simulation and after-sales service (value proposition), customer service (customer relations), and presentations/exhibitions (cost structure).

The percentage changes of total-degree centrality in particular business model components are both positive and negative. The highest (percentage) change (loss of value) was noted by the personal contact node, by $6.25 \%$. After eliminating the people component (e.g., the most knowledgeable staff lost), most nodes noted a fall in their rank (loss of significance and weaker potential impact of particular components) of between $-1.19 \%$ and $-6.25 \%$. Despite removing a key network node, the resistance to change of the whole network (networked relations of the business model) amounted to 0.555 , whereas the number of relations fell from 199 to 170 (before removing the component, the network density was 0.582 ). This did not affect the potential fragmentation of the network and the dispersion of the nodes (lack of connection with other nodes). 


\section{Implications of the study}

The findings contribute to the literature on business models and business model innovations. Current literature recognizes the potential of networks to study and understand the complexity of business models, interactions and interdependencies of their components that can be developed in the context of assessing the effectiveness of a business model (e.g., resource allocation), organizational risks, and creating value using sophisticated techniques of organizational network analysis. We show how to identify the interdependence of networks, how to analyze the causal relationships of a business model based on the identified components, and finally, how to simulate changes towards positive and negative scenarios related to business models. More forward-looking research, including the morphology of the components, their logically unpredictable combination, can contribute to the development of a business model innovation based on a surprising component configuration that can result in the creation of innovative value for customers.

The theoretical background presented in the paper aims at defining a business model from the perspective of resource, network, and dynamic approaches. The resource approach describes the business model taking into account the set of resources (both tangible and intangible), which constitute the essential business model components determining value creation. The network approach enables one to define the business model as a network of interrelated components that affect each other in unilateral or mutual relations. Finally, the dynamic approach to the business model is based on the network of relations between its components, with a key role played by the simulation of changes via creating (positive or negative) scenarios related to the loss or excess of resources (components) of the business model. The above-listed approaches affect the level of sustainability demonstrated by the business model's ability or inability to create value. The less sustainable the business model (possessing unrelated components that can create synergies), the bigger the risk of value loss or damage. The theoretical implications can be associated with methods used in assessing the company's business competences and with the network analysis itself. Developing a business model nowadays requires an interdisciplinary approach to analyzing the business capabilities of a company, expressed in the use of methods that, in a complementary way, would allow the creation of a real picture of the implemented business venture.

The study presented in the paper uses network analysis to analyze a virtual reality company's business model and to provide information to analysts and managers responsible for developing vision and strategy, as well as value creation for the company. The dynamic and resource approach is a useful perspective in assessing the company's business capabilities, designing new ventures, and monitoring the resistance to change of the business model. By specifying the components that are key to value creation, we can identify the nodes and their attributes needed to perform network analysis. The practical implications of the method used to study business models are expressed in the benefits of using network analysis as a complementary tool to the traditional methods of the economic analysis of an enterprise, by obtaining information on the resource interdependence, their actual value, usability, impact on other resources (components), or dynamics of change over time. Network analysis allows one to look at company resources from a different perspective; mere possession of resources may not necessarily indicate business potential. The value of owned resources can be expressed in the company's ability to use them and develop those that have the greatest impact on creating value or achieving the company's goals.

Each company has a huge amount of data that is collected in virtual systems supporting business management. However, the actual value of this data can only be assessed when we find out what the data is, and how and for what purposes it is used in the company. We can get this information by analyzing the relationships between employees, tasks, data, and information used by employees. Network analysis makes it possible to identify employee behavior, and their relationships with other enterprise resources like knowledge, skills, commitment, availability, etc., to gain more understanding of knowledge, resource or task congruence, and redundancy. In an advanced analysis, building a one-mode or two-mode matrix can take place based on more complex, more detailed components of the business model, which would allow the creation of a broader picture of owned, used resources, and performed tasks.

By discovering the most prominent (central) network nodes, it becomes possible to determine the rank of individual resources in value creation. The possibilities of simulating the presence of particular nodes in the business model can contribute to gathering valuable sources of information for identifying investment needs and existing organizational risks, optimizing costs, and, subsequently, managing tangible and intangible resources in the company. Especially, as network metrics (e.g., density, centralities) allow managers to examine the level of cross-linking, and indicate the level of, for instance, over/underused resources. The ability to perform simulations, e.g. by adding and subtracting nodes, can predict in advance the consequences and potential changes in business model, monitor and forecast changes, and is not limited to reactive identification and assessment of events.

In the context of sustainability of the business model, organizational network analysis becomes a unique tool for decision-makers. Creating "what if" scenarios in which there is a risk of removing a given component (e.g., lack of resources or partners), or removing the relationship (e.g., strong links between components), or the type of relationship (e.g., task 
interdependence) could help decision-makers to prevent and prepare for market influences. Based on the elimination of the selected (most central) component of the business model, it was shown how the sustainability of the business model can be assessed in the context of positive (i.e., obtaining additional resources) and negative (i.e., loss of key partners) organizational scenarios and risks. Simulating changes in the business model, based on the random number of nodes/ties to remove, would show the differences in values between the original and the modified network. The decision-maker can also choose the number of iterations to be performed, thus enabling the assessment of the network susceptibility to accidental node/tie removal. Comparative statistical techniques are used to evaluate networks with and without nodes. The decision-maker identifying the network also identifies the node/tie or nodes/ ties to be removed, and then calculates the resulting changes in the network, removing these nodes in terms of the overall structure of the network and key elements. Then, one can save the network with removed nodes/ties and evaluate the modified network using other network metrics (e.g., betweenness centrality, eigenvector centrality). Change analysis is designed to help decision-makers understand how removing a node/tie, or a number of nodes/ties, can affect the operation of the entire network (e.g., business model, business process, organization, or strategic alliance). Change analysis allows managers to select specific nodes/ties in the network to delete, and then compare different metrics between the original network and the network in which those specific nodes/ties are removed, causing fragmentation or clusters (cliques).

\section{Limitations and directions for further research}

In the paper, we did not refer to the market-based view (e.g., Makhija 2003), because the business model is analyzed from an intra-organizational perspective (c.f., Ujwary-Gil 2019). The market-based view focuses on the environment of a company operating and competing on selected markets, where the sources of value for the company are embedded in the competitive situation that characterizes its external product markets. Determining the actual relationships between external partners (stakeholders) and other enterprise resources, as well as monitoring the dynamics of external relations as a result of the involvement of resources on both sides of the partnership, e.g., people, information or communication systems used, would allow the assessment of the impact of external relationships on value creation. In the future, the aspect of resistance to change and a sustainable business model from a market and inter-organizational based view requires further, in-depth analysis. It has been assumed that resistance to change (at least in the expected, short term) and a sustainable business model can be measured using sophisticated network techniques and change simulations.

Presenting the network using a binary, one-mode, adjacency matrix is a simplification of the impact of various components of the business model, which is not always 0 and 1. It is a dynamic continuum, which can be expressed in valued matrices. To achieve this, however, mathematically revised network measures are necessary, taking into account, for example, the strength of relationships or the intensity of changes. The presentation of the business model components is the starting point for further in-depth analysis. It is evident that the removal of the people component should not be taken literally, because no company, at least for today, can exist without people. It is only an exemplification of the dynamics of the business model, and people are treated here as a comprehensive, and only one of its components, without detailed analysis (e.g., employees' competence, their skills, knowledge, experience, tenure, age, position in the company, etc.). The relationship and interdependence analysis should be carried out by means of a survey involving employees of the company being analyzed. This would allow for a more profound identification of relationships between individual employees (actors), analysis of their behavior, relationships with other employees, their prominent or peripheral position in the network (organization), dependence on resources, or tasks. Knowledge of interpersonal relationships in connection with non-human nodes (e.g., resources, tasks) is also a prerequisite for measuring the efficiency of resource use, or tasks performed in an organization that has adopted a specific business model for its activities. The data should be used to develop the final shape of a onemode or two-mode matrix to minimize the subjective outcome. The study shows the initial stage of a general approach to business model components. The human node (one of the components of the business model) was used because of the vital importance of this node in an IT company creating virtual reality products. The decomposition of the human node, as well as other components of the business model in further studies, will allow for more detailed analysis. For any other organization, research questions can be formulated to include components of a business model, particularly sensitive to organizational performance.

Moreover, we should identify several positive (adding nodes or relations) and negative (losing nodes or relations) scenarios for the simulation of the network structure to diagnose the risk of the business model to the company's operation. Our research was limited only to the loss of one prominent node (component) in the network (business model) to demonstrate how such an analysis may be applied to a more advanced study and more detailed business models or complex dynamics of relations generated by a greater number of components. The exemplification of a single study can only produce preliminary results in relation to the phenomenon in 
question, which is the business model. Hence, larger-scale research is needed, including multiple-case research.

The paper was intended to fill a specific gap connected with the dynamic and network views of the virtual reality company's business model and its components. Through the analysis of network metrics, it was possible to measure (quantitatively) changes in the business model and its components. The dynamic presentation of business models, however, calls for further, more extensive research, taking into account the time factor and much more complex components of business models. By measuring the value proposition component and its attributes, we would be able to demonstrate the direct impact of the identified components on the change in value creation for clients. The analysis of relations is a valuable approach, since we do not analyze nodes separated from each other (though, in extreme cases they might be isolated), but as an interrelated whole - the business model, which dynamics is worth knowing through interactions shedding some light on how value is created in a company. Given the growing importance of digital competences in virtual reality, understood as strategic enterprise resources, there will be a growing demand for theory analyzing the complexity of relationships between social, technical and digital components of the business model. The presented exemplification of the business model, studied using organizational network analysis, can be considered as a promising starting point for more detailed research.

\section{Conclusion}

The paper uses organizational network analysis applied in a unique context - to examine the network of relations existing between the components (nodes) of a virtual reality company's business model (network). Although we relied on basic network measures, such as density; total-degree; out- and in-degree centralities, they concerned a new research area - the business model of a virtual reality company. Within the presented study, we discussed the activities of the company, which operates in the virtual reality sector. By describing its activities, we pointed to the uniqueness of the solutions (services, products) proposed to clients.

Moreover, we developed the one-mode (adjacency) matrix, which is a starting point for measuring, visualizing, and simulating the network of relations between business model components. In the matrix, we marked strong relations (strong impact) between particular components. The choice of the business model components was based on the practical concept developed by Osterwalder and Pigneur (2010), tailored to the analyzed study. The choice of this concept was also determined by the EU project (IAPP), dedicated to this popular solution.

The questions formulated for research purposes reflect the applied research approach. In the first place (RQ 1), the most prominent nodes in the network were identified, in our study, the components in the business model of the virtual reality company. In the second (RQ 2), observations of changes in the tested model were carried out after the removal of one of the prominent nodes. Thirdly (RQ 3), the resistance to change of the business model was assessed based on the observed change in the cross-linking of the relationships between the tested components. According to the assumption, the value of the network density changed after removing one node, and changes in the ranking of individual components were also observed.

The level of network changes may mean a threat to the efficiency of the organization due to the reduced use of resources or the lack of access to selected resources, etc. Changes in network density may also initiate activities for the selection of resources, the importance of which in achieving the goals of business processes is small, or reduce the profitability of undertaken ventures. However, such a detailed interpretation of the results for the needs of practical application requires more advanced and longitudinal studies, which are recommended in the paper.

The assessment of the results obtained, primarily the interpretation of the size of deviations, can provide information in the process of developing a sustainable business model. The use of organizational network analysis techniques to analyze business models is possible for simultaneous analysis when the business model is being developed or implemented. Assumptions about sustainable development can be applied, provided the decision-maker knows the consequences of planned changes in the business model. Research using organizational network analysis can provide such knowledge, especially regarding resources and tasks, which help to detect risks at an early stage when developing a sustainable business model.

Acknowledgments The authors would like to thank all anonymous reviewers and the editors for their helpful comments and suggestions, which influenced the final version of this paper very much. This work has been supported by statutory funds of Institute of Economics, Polish Academy of Sciences and Cognitione Foundation for the Dissemination of Knowledge and Science. The authors acknowledge the support of Marie Curie Industry-Academia Partnerships and Pathways Programme (IAPP) - project number 324448.

Open Access This article is licensed under a Creative Commons Attribution 4.0 International License, which permits use, sharing, adaptation, distribution and reproduction in any medium or format, as long as you give appropriate credit to the original author(s) and the source, provide a link to the Creative Commons licence, and indicate if changes were made. The images or other third party material in this article are included in the article's Creative Commons licence, unless indicated otherwise in a credit line to the material. If material is not included in the article's Creative Commons licence and your intended use is not permitted by statutory regulation or exceeds the permitted use, you will need to obtain permission directly from the copyright holder. To view a copy of this licence, visit http://creativecommons.org/licenses/by/4.0/. 


\section{References}

Alcadipani, R., \& Hassard, J. (2010). Actor-network theory, organizations and critique: Towards a politics of organizing. Organization, 17(4), 419-435. https://doi.org/10.1177/1350508410364441.

Altman, N., Carley, K. M., \& Reminga, J. (2017). ORA user's guide 2017. Carnegie Mellon University, School of Computer Science, Institute for Software Research, Pittsburgh, Pennsylvania, technical report CMU-ISR-17-100.

Amit, R., \& Zott, C. (2001). Value creation in E-business. Strategic Management Journal, 22(6-7), 493-520. https://doi.org/10.1002/ smj.187.

Amit, R., \& Zott, C. (2012). Creating value through business model innovation. MIT Sloan Management Review, 53(3), 36-44.

Balboni, B., \& Bortoluzzi, G. (2015). Business model adaptation and the success of new ventures. Journal of Entrepreneurship, Management and Innovation, 11(1), 119-140. https://doi.org/10.7341/20151117.

Barney, J. (1991). Firm resources and sustained competitive advantage. Journal of Management, 17(1), 99-120. https://doi.org/10.1177/ 014920639101700108

Barney, J. B. (2001). Resource-based theories of competitive advantage: A ten-year retrospective on the resource-based view. Journal of Management, 27(6), 643-650. https://doi.org/10.1177/ 014920630102700602

Beattie, V., \& Smith, S. J. (2013). Value creation and business models: Refocusing the intellectual capital debate. The British Accounting Review, 45(4), 243-254. https://doi.org/10.1016/j.bar.2013.06.001 .

Blackler, F. (1993). Knowledge and the theory of organizations: Organizations as activity systems and the reframing of management. Journal of Management Studies, 30(6), 863-884. https://doi.org/10. 1111/j.1467-6486.1993.tb00470.x.

Blaschke, M., Riss, U., Haki, K., \& Aier, S. (2019). Design principles for digital value co-creation networks: A service-dominant logic perspective. Electronic Markets, 29(3), 443-472. https://doi.org/10. 1007/s12525-019-00356-9.

Bocken, N. M. P., Short, S. W., Rana, P., \& Evans, S. (2014). A literature and practice review to develop sustainable business model archetypes. Journal of Cleaner Production, 65, 42-56. https://doi.org/10. 1016/j.jclepro.2013.11.039.

Borgatti, S. P., Everett, M. G., \& Johnson, J. C. (2018). Analyzing social networks. London: SAGE Publications.

Breuer, H., \& Lüdeke-Freund, F. (2016). Values-based network and business model innovation. International Journal of Innovation Management, 21(03), 1750028. https://doi.org/10.1142/ S1363919617500281.

Carley, K., Pfeffer, J., Reminga, J., Storrick, J., \& Columbus, D. (2018). ORA user's guide. Pittsburgh, PA: Carnegie-Mellon University.

Dellyana, D., Simatupang, T. M., \& Dhewanto, W. (2016). Business model innovation in different strategic networks. International Journal of Business, 21(3), 191-215.

Demil, B., \& Lecocq, X. (2010). Business model evolution: In search of dynamic consistency. Long Range Planning, 43(2-3), 227-246. https://doi.org/10.1016/j.lrp.2010.02.004.

Everton, S. F. (2012). Disrupting dark networks. Cambridge, UK: Cambridge University Press.

Fallahi, S., Kirchberger, M., \& Gassmann, O. (2017). Adapt and strive how ventures under resource constraints create value through business model. Creativity and Innovation Management Journal, 26(3), 233-246. https://doi.org/10.1111/caim.12218

Foss, N. J., \& Saebi, T. (2017). Fifteen years of research on business model innovation: How far have we come, and where should we go? Journal of Management, 43(1), 200-227. https://doi.org/10. $1177 / 0149206316675927$.
Freeman, L. C. (1978). Centrality in social networks conceptual clarification. Social Networks, 1(3), 215-239. https://doi.org/10.1016/ 0378-8733(78)90021-7.

Freiling, J. (2015). Business model innovation - A concept between organizational renewal and industry transformation. Journal of Entrepreneurship, Management and Innovation, 11(1), 3-10. https://doi.org/10.7341/20151111.

Günzel-Jensen, F., \& Holm, A. B. (2015). Freemium business models as the foundation for growing an e-business venture: A multiple case study of industry leaders. Journal of Entrepreneurship, Management and Innovation, 11(1), 77-101. https://doi.org/10. $7341 / 20151115$.

Hacklin, F., Björkdahl, J., \& Wallin, M. W. (2018). Strategies for business model innovation: How firms reel in migrating value. Long Range Planning, 51(1), 82-110. https://doi.org/10.1016/j.lrp.2017. 06.009 .

Hedman, J., \& Kalling, T. (2003). The business model concept: Theoretical underpinnings and empirical illustrations. European Journal of Information Systems, 12(1), 49-59. https://doi.org/10. 1057/palgrave.ejis.3000446.

Jablonski, A., \& Jablonski, M. (2016). Research on business models in their life cycle. Sustainability, 8(5), 430. https://doi.org/10.3390/ su8050430.

Johnson, M. W., Christensen, C. M., \& Kagermann, H. (2008). Reinventing your business model. (cover story). Harvard Business Review, 86(12), 50-59.

Jokela, P., \& Elo, M. (2015). Developing innovative business models in social ventures. Journal of Entrepreneurship, Management and Innovation, 11(1), 103-118. https://doi.org/10.7341/20151116 .

Kaplan, R. S., \& Norton, D. P. (1992). The balanced scorecard-measures that drive performance. Harvard Business Review, 70(1), 71-79.

Kasztler, A., \& Leitner, K. H. (2009). An SNA/based approach for management control of intellectual capital. Journal of Intellectual Capital, 10(3), 329-340. https://doi.org/10.1108/ 14691930910977761.

Li, R., Zhang, Z., Li, F., \& Ahokangas, P. (2018). A shared network access business model for distribution networks. IEEE Transactions on Power Systems, 33(1), 1082-1084. https://doi.org/ 10.1109/TEC.2017.2688137.

Linder, M., \& Williander, M. (2017). Circular business model innovation: Inherent uncertainties. Business Strategy and the Environment, 26(2), 182-196. https://doi.org/10.1002/bse.1906.

Lüdeke-Freund, F., \& Dembek, K. (2017). Sustainable business model research and practice: Emerging field or passing fancy? Journal of Cleaner Production, 168, 1668-1678. https://doi.org/10.1016/j. jclepro.2017.08.093.

Makhija, M. (2003). Comparing the resource-based and market-based views of the firm: Empirical evidence from Czech privatization. Strategic Management Journal, 24(5), 433-451. https://doi.org/10. 1002/smj.304.

Merrill, J., Caldwell, M., Rockoff, M. L., Gebbie, K., Carley, K. M., \& Bakken, S. (2008). Findings from an organizational network analysis to support local public health management. Journal of Urban Health: Bulletin of the New York Academy of Medicine, 85(4), 572-584. https://doi.org/10.1007/s11524-008-9277-8.

Morris, M., Schindehutte, M., \& Allen, J. (2005). The entrepreneur's business model: Toward a unified perspective. Journal of Business Research, 58(6), 726-735. https://doi.org/10.1016/j.jbusres.2003. 11.001.

Nair, S., Nisar, A., Palacios, M., \& Ruiz, F. (2012). Impact of knowledge brokering on performance heterogeneity among business models. Management Decision, 50(9), 1649-1660. https://doi.org/10.1108/ 00251741211266732 .

Osterwalder, A., \& Pigneur, Y. (2010). Business model generation: A handbook for visionaries, game changers, and challengers (1st ed.). Hoboken, NJ: John Wiley and Sons. 
Otto, B., \& Jarke, M. (2019). Designing a multi-sided data platform: Findings from the international data spaces case. Electronic Markets, 29(4), 561-580. https://doi.org/10.1007/s12525-01900362-x.

Penrose, E. T. (1995). The theory of the growth of the firm. Oxford, UK: Oxford University Press.

Peppard, J., \& Rylander, A. (2001). Using an intellectual capital perspective to design and implement a growth strategy: The case of APiON. European Management Journal, 19(5), 510-525. https://doi.org/10. 1016/S0263-2373(01)00065-2.

Pike, S., Roos, G., \& Marr, B. (2005). Strategic management of intangible assets and value drivers in $\mathrm{R} \& \mathrm{D}$ organizations. $R \& D$ Management, 35(2), 111-124. https://doi.org/10.1111/j.1467-9310.2005.00377.x.

Prell, C. (2012). Social network analysis: History, theory and methodology. London: SAGE Publications.

Priem, R. L., Wenzel, M., \& Koch, J. (2017). Demand-side strategy and business models: Putting value creation for consumers center stage. Long Range Planning, 51(1), 22-31. https://doi.org/10.1016/j.lrp. 2017.07.007.

Rajakallio, K., Ristimäki, M., Andelin, M., \& Junnila, S. (2017). Business model renewal in context of integrated solutions delivery: A network perspective. International Journal of Strategic Property Management, 21(1), 72-86. https://doi.org/10.3846/1648715X. 2016.1249533.

Rogers, E. M. (2003). Diffusion of innovations (5th ed.). New York: Simon and Schuster.

Sanchez, P., \& Ricart, J. E. (2010). Business model innovation and sources of value creation in low-income markets. European Management Review, 7(3), 138-154. https://doi.org/10.1057/emr. 2010.16.

Schiuma, G. (2009). The managerial foundations of knowledge assets dynamics. Knowledge Management Research \& Practice, 7(4), 290-299. https://doi.org/10.1057/kmrp.2009.21.

Sorescu, A. (2017). Data-driven business model innovation. Journal of Product Innovation Management, 34(5), 691-696. https://doi.org/ 10.1111/jpim.12398.

Straker, K., \& Wrigley, C. (2015). The role of emotion in product, service and business model design. Journal of Entrepreneurship, Management and Innovation, 11(1), 11-28. https://doi.org/10. $7341 / 20151112$.

Suherman, A. G., \& Simatupang, T. M. (2017). The network business model of cloud computing for end-to-end supply chain visibility. International Journal of Value Chain Management, 8(1), 22-39. https://doi.org/10.1504/IJVCM.2017.082684.

Tichy, N. M., Tushman, M. L., \& Fombrun, C. (1979). Social network analysis for organizations. Academy of Management Review, 4(4), 507-519.
Trapp, M., Voigt, K.-I., \& Brem, A. (2017). Business models for corporate innovation management: Introduction of a business model innovation tool for established firms. International Journal of Innovation Management, 22(01), 1850007. https://doi.org/10. 1142/S136391961850007X.

Tsvetovat, M., \& Carley, K. M. (2004). Modeling complex sociotechnical systems using multi-agent simulation methods. Kunstliche Intelligenz, 18(2), 23-28.

Ujwary-Gil, A. (2017). The business model and intellectual capital in the value creation of firms: A literature review. Baltic Journal of Management, 12(3), 368-386. https://doi.org/10.1108/BJM-102016-0224.

Ujwary-Gil, A. (2019). Organizational network analysis: A study of a university library from a network efficiency perspective. Library \& Information Science Research, 41(1), 48-57. https://doi.org/10. 1016/j.lisr.2019.02.007.

Ujwary-Gil, A. (2020). Organizational network analysis : Auditing intangible resources. New York: Routledge. https://doi.org/10.4324/ 9780367408947.

Valente, T. W. (2010). Social networks and health. Oxford, UK: Oxford University Press.

Wasserman, S., \& Faust, K. (1994). Social network analysis: Methods and applications. Cambridge: Cambridge University Press.

Weking, J., Mandalenakis, M., Hein, A., Hermes, S., Böhm, M., \& Krcmar, H. (2019). The impact of blockchain technology on business models-a taxonomy and archetypal patterns. Electronic Markets, 30, 1-21. https://doi.org/10.1007/s12525-019-00386-3.

Wirtz, B. W., Pistoia, A., Ullrich, S., \& Göttel, V. (2016). Business models: Origin, development and future research perspectives. Long Range Planning, 49(1), 36-54. https://doi.org/10.1016/j.lrp. 2015.04.001.

Yip, A. W. H., \& Bocken, N. M. P. (2018). Sustainable business model archetypes for the banking industry. Journal of Cleaner Production, 174, 150-169. https://doi.org/10.1016/j.jclepro.2017.10.190.

Zott, C., \& Amit, R. (2010). Business model design: An activity system perspective. Long Range Planning, 43(2-3), 216-226. https://doi. org/10.1016/j.lrp.2009.07.004.

Zott, C., Amit, R., \& Massa, L. (2011). The business model: Recent developments and future research. Journal of Management, 37(4), 1019-1042. https://doi.org/10.1177/0149206311406265.

Publisher's note Springer Nature remains neutral with regard to jurisdictional claims in published maps and institutional affiliations. 